RESEARCH NOTE

\section{First Report of Haematobia irritans (L.) (Diptera: Muscidae) as Vector of Dermatobia hominis (L.jr.) (Diptera: Cuterebridae) in Minas Gerais, Brazil}

\author{
RC Leite/ ${ }^{+}, \mathrm{Z}$ Rodríguez, \\ JLH Faccini*, PR Oliveira, \\ AA Fernandes
}

Departamento de Medicina Veterinária Preventiva,

Escola de Veterinária, Universidade Federal de Minas Gerais, Campus da Pampulha, Av. Antônio Carlos 6627, 312670-100 Belo Horizonte, MG, Brasil

*Departamento de Parasitologia Animal, Instituto de Biologia, Universidade Federal Rural do Rio de Janeiro, km 47 da Antiga Rodovia Rio-São Paulo, 23851-082 Seropédica, RJ, Brasil

Key words: Dermatobia hominis - biological vector Haematobia irritans

Biological transmission of eggs and larvae of the human bot fly Dermatobia hominis by a female of the horn fly Haematobia irritans is reported for the first time in South America. Seventeen females of $H$. irritans were collected near the municipality of Morada Nova $\left(19^{\circ} \mathrm{S}, 45^{\circ} \mathrm{W}\right)$ in the Três Marias, region of northwestern Minas Gerais in June 1993 and sent to the Entomology Laboratory, Dept. of Prevention Veterinary Medicine, Veterinary School of the Federal University of
Minas Gerais for identification based on the keys of B Greenberg (1971 Flies and Diseases: Ecology, Classification and Biotic Associations, Princeton University Press, Princeton, 483 pp.) (Fig. 1).

One of the flies bore 21 viable eggs of $D$. hominis which were incubated in a BOD oven at $27^{\circ} \mathrm{C}$ and $80 \% \mathrm{RH}$. Hatching of first instar larvae was observed after four days. Various authors (A Neiva \& JF Gomes 1917 An Esc Pau Med Cir 8: 197-209, JT Greighton \& WW Neel 1952 Turrialba 2: 59-65) have cited a five-day mean incubation period for $D$. hominis eggs.

The viability of recently eclosed larvae was demonstrated by host-seeking behaviour consisting of vibratory movements and projection of the anterior part of the body in response to stimulation with heat and $\mathrm{CO}_{2}$ (Fig. 2). Four larvae were used for experimental inoculation of a rabbit (Oryctolagus cuniculus) where they completed their larval development. These observations of the emergence of $D$. hominis larvae transported by $H$. irritans suggest that the latter species could be an efficient biological vector of the human bot fly.

The importance of this report lies in the fact that $H$. irritans had never been implicated in the transportation of eggs of $D$. hominis (PT Artigas \& RG Serra 1965 Ciênc Cult 17: 21-29, JH Guimarães et al. 1983 Rev Bras Zool 4: 239-416, Z Rodríguez 1987 Ocorrência e Distribuição de Larvas de Dermatobia hominis (L. Jr., 1781) em Bovinos e Flutuação de Dípteros Sinantrópicos Rurais, Msc Thesis, UFPel, 70 pp., N Kasai et al. 1990 Rev Bras Entomol 34: 369-380). The high population densities and behavioural characteristics of $H$. irritans (permanent and close association with cattle, punctuated by brief, slow flights away from the bodies of the animals) would seem to predispose it to parasitism by $D$. hominis and the establishment of the horn fly in South America (MR Honer et al. 1990 Embrapa-CNPGC, Circ Tec 45, p. 34) could increase the problem of human bot fly infestations in areas where the latter species is endemic.

\footnotetext{
${ }^{+}$Corresponding author. Fax: +55-31-499-2080.

E-mail: rcleite@ dedalus.lcc.ufmg.br

Received 13 February 1998

Accepted 24 August 1998
} 


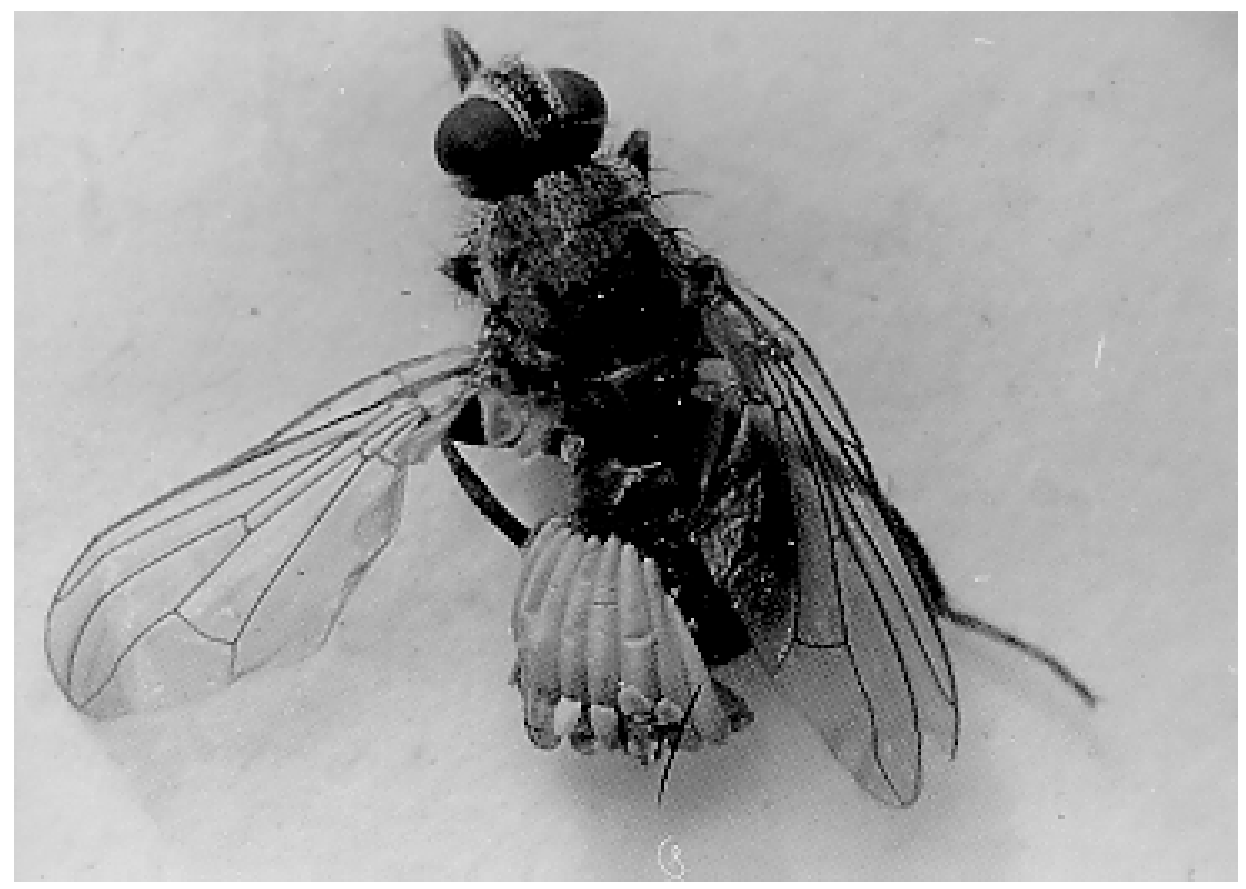

Fig. 1: Haematobia irritans with eggs of Dermatobia hominis adhering to the abdomen.

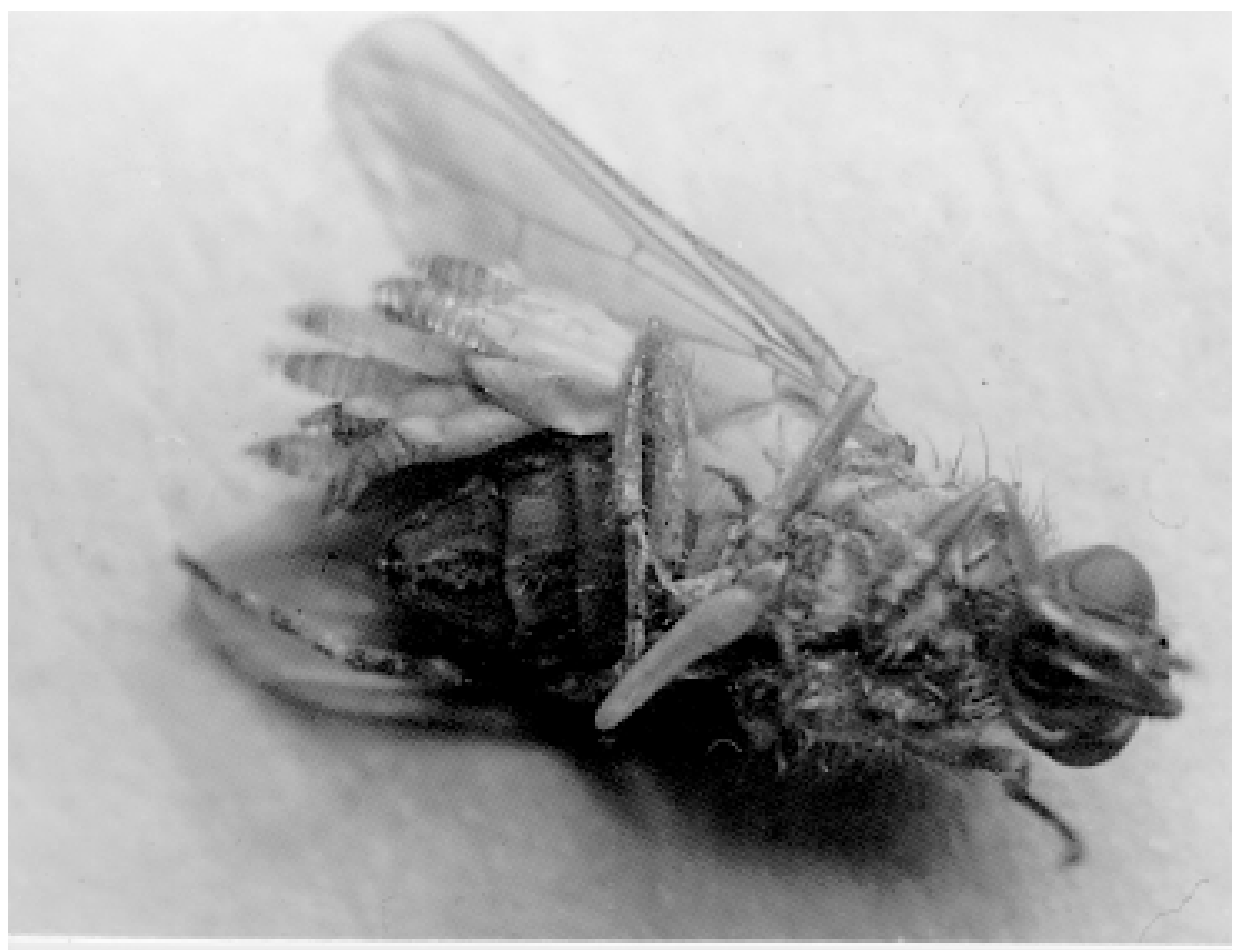

Fig. 2: first instar larvae of Dermatobia hominis subjected to stimulation with heat and carbon dioxide. 